\title{
An Interdisciplinary 4th Level Education Model:Connected Health
}

\author{
Mountford, Nicola ${ }^{a}$; Kessie, Threase ${ }^{\text {b}}$; Watts, Gemma ${ }^{\text {b }}$; Fernandez, Luis ${ }^{\text {c }}$; \\ Chouvarda, Ioanna ${ }^{\mathrm{d}}$; and Cusack, Tara ${ }^{\mathrm{b}}$ \\ ${ }^{\text {a }}$ Smufit School of Business, University College Dublin, Ireland, ${ }^{b}$ UCD School of Public \\ Health Physiotherapy and Sports Science, University College Dublin, Ireland, 'Salumedia, \\ Seville, Spain and Qatar Computing Research Institute, Qatar, ${ }^{\mathrm{d}}$ Laboratory of Computing, \\ Medical Informatics and Biomedical-Imaging Technologies, Aristotle University of \\ Thessaloniki, Greece.
}

\begin{abstract}
This paper responds to the need for interdisciplinary approaches to fourth level education that better reflect the complexity of the world in which we work and conduct research. We discuss this need in technology-enabled healthcare, Connected Health. We propose a model for fourth level interdisciplinary education and discuss its trial application in two European structured PhD programmes in the Connected Health research arena. We suggest broader learning objectives for the emerging fourth level graduate, methods of incorporating multiple disciplinary inputs and perspectives into deep disciplinary PhD training, intersectoral approaches to ensure employability and impact, and innovative training methods and structures to facilitate interdisciplinary and intersectoral learning. We give some examples of innovative training modules used within the pilot programmes. Finally we discuss six core elements of a truly interdisciplinary programme at fourth level - exposure to different environments, joint supervision, a genuine role for the non academic sector, career development training and planning, the development of a sustainable training network beyond the life of the programme, and data openness.
\end{abstract}

Keywords: Fourth Level; Interdisciplinary; Intersectoral, Models, Innovative Methods, Connected Health. 


\section{Introduction: The Need for Interdisciplinarity in Connected Health $(\mathrm{CH})$}

As the population aged over 60 almost doubles (U.N., 2015), healthcare costs will become unsustainable. $\mathrm{CH}$ offers a new health management model combining state-of-the-art technologies, tools, and methodologies. (Caulfield \& Donnelly, 2013). Although 80\% of EU countries have an eHealth strategy (Enject, 2016), implementation lags due to lack of evidence of effectiveness; few data management standards; privacy/security concerns; old reimbursement models; and resistance to change (Anderson, 2007; AT\&T, 2012; Accenture, 2012). These challenges are poorly addressed by siloed approaches at both research and practice levels. Technology alone is not sufficient to address health needs but must be integrated "into the care and services that are delivered" (UK Dept of Health, 2011) as many Research and Development projects fail to reach market. We propose an interdisciplinary education model that encourages "professionals [to] learn with, from and about each other to improve collaboration and the quality of care" (CAIPE, 1997). We suggest broader learning objectives, and isolate the six core elements of a truly interdisciplinary programme at fourth level. This paper explores the conceptual underpinnings and development processes employed to develop two structured $\mathrm{PhD}$ programmes (Innovative Training Networks under EU Marie Skłodowska-Curie Actions MSCA). These progammes were specifically designed to exploit interdisciplinarity and in so doing develop $\mathrm{CH}$ champions of the future. This paper introduces the concept of $\mathrm{CH}$, examines the concepts underpinning the interdisciplinary $\mathrm{CH} \mathrm{PhD}$ programmes and describes how interdisciplinary and intersectoral elements are employed within the $\mathrm{PhD}$ training and secondment programmes.

$\mathrm{CH}$, as a market and as a scientific field (Swan, 2009), requires "T-shaped" individuals for its research and practice workforces (Figure 1). We must expose the next generation of $\mathrm{CH}$ contributors to the different contexts in which they will work. We must develop within them a new relationship with their colleagues from other disciplines - one based on understanding, trust, and confidence. We must help them to reevaluate their understanding of 'real life' - prioritizing their patient's needs, and valuing what their patients can bring to the table in terms of the lived experience. Our model reflects the fact that this is best achieved through the concrete experience gained while learning 'in context' (Kolb, 1984). Graduates from our model programmes will ally deep disciplinary expertise (state-of-theart theory, practice and research value in their domain) to a broad understanding of contextual domains (including business, economics, engineering) and the life, health, computer and social sciences. Such $\mathrm{CH}$ "champions" will together construct a new understanding of the complex, interconnected challenges across the education, industry, health, and policy sectors. This reflects the constructivist learning theory that fundamentally underpins our programme design. Students take what they already know, integrate it with a 
new experience or learning, creating truly novel understandings for themselves due to the interdisciplinary context in which the learning is constructed (Ertmer \& Newby, 1993).

\section{The Programmes}

While all MSCA programmes encourage the involvement of industry, the formalization of secondments, intersectoral approaches, and transferable skills, our programmes go beyond these criteria. They represent a genuine effort to redefine $\mathrm{PhD}$ education in $\mathrm{CH}$. No other European $\mathrm{CH}$ projects involve structured PhD training (CORDIS, 2017). ENJECT (2016) finds only half of healthcare professional training programmes deal with $\mathrm{CH}$, most focused on medical informatics or data analytics. No programmes span the necessary range of disciplines because of the difficulty in their inception (expertise across disciplines), delivery (structure and cohesion across disciplines), and translation (multi-sector input and application). We are creating a unique cohort of 23 "T-shaped" researchers (Figure 1). Graduates arrive with domain credibility and depth, and deepen this in their $\mathrm{PhD}$ project (vertical of the ' $\mathrm{T}$ '). What distinguishes these programmes, however, is the horizontal capping of the ' $\mathrm{T}$ ' through intersectoral learning within secondments, and interdisciplinary learning within the training programme.

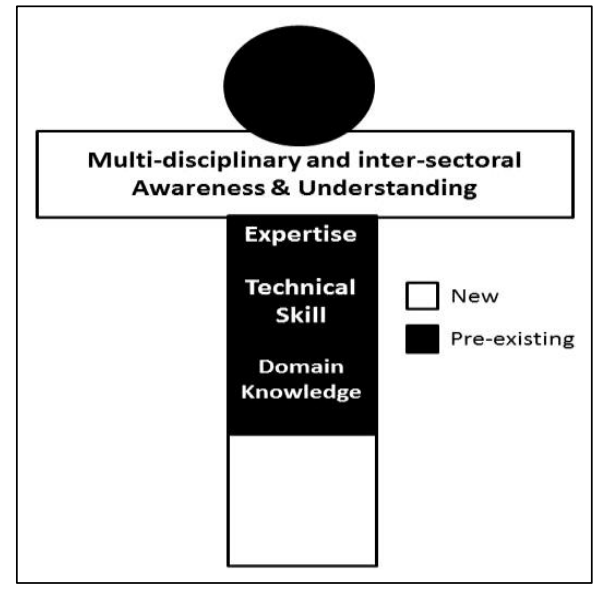

Figure 1: The "T-shaped" researcher, illustrates how students develop the traditional expertise and skill associated with PhD coupled with additional learning as part of a multi-discipinary and intersectoral community.

The programmes are built on 6 elements: deep domain expertise ( $\mathrm{PhD}$ project/ intersectoral secondment), broad education (introductory seminars to each discipline), research skills, integrating activities, career development, and open sharing of data. Each is designed for interdisciplinary learning with communications skills training for intersectoral and interdisciplinary communications, and career development for roles at the intersection of disciplines and sectors.Events encourage formal and informal interdisciplinary/intersectoral networking and collaboration. Modules such as the $\mathrm{CH}$ index, bring students together to 
identify and weight multi-factorial impacts on $\mathrm{CH}$ adoption from varied disciplinary and professional perspectives. Concurrent workpackages promote state of the art and crosspollinate, enabling further interdisciplinary learning as well as industry-relevance. Industry includes multi-national corporations (MNCs), small to medium sized enterprises (SMEs), hospitals and charities. Interdisciplinary programmes facilitate engagement by supporting diversity, participation, connections, and interactive teaching and learning, students report positive experiences (Newswander \& Borrego, 2009).

Intersectoral secondments ensure an ability to operate in both academic and non-academic environments and broaden the researcher's networks and frame-of-reference. Professional learning develops as students role-model individuals/professionals already working within $\mathrm{CH}$. The tacit learning and nuances which are only developed with exposure to the sector are strikingly evident on students' return from secondment. This situated learning reflects our belief that knowledge cannot be taught in the abstract and, to be useful, must be situated in a relevant or "authentic" context. Events are also opened up to non-programme research leaders, students, clinicians, and industries to further develop student networks, experiences, and skills. Programme websites facilitate peer-to-peer training and networking through forum and collaborative tools (see www.chessitn.eu) supported by social media training. Collaborative writing workshops (in conjunction with ENJECT) facilitate and equip students for joint publication.

\subsection{CHESS (CH Early Stage Researcher Support System) www.chessitn.eu}

CHESS will develop a model for the co-production of health with multi-stakeholder input, facilitating the end-to-end, interdisciplinary design of $\mathrm{CH}$ research programmes, pilot deployments, and evaluation techniques to increase and expedite adoption of $\mathrm{CH}$ models. It does this through $15 \mathrm{PhDs}$ across four work packages: care, change, data and sustainability.

\subsection{CATCH (Cancer: Activating Technology for $\mathrm{CH}$ ) www.catchitn.eu}

CATCH will bridge the gap between cancer survivors' depleted physical and emotional state, and their ability to return to a fully functional societal role through technologysupported physical exercise by a) understanding the nature and scale of the problem facing cancer survivors attempting to return to a full societal role, b) examining a variety of possible technology interventions, and c) investigating methods of selling and scaling these technology solutions. 


\section{Innovative Training Modules for Interdisciplinarity}

European $\mathrm{CH}$ Index: CHESS will develop a $\mathrm{CH}$ index to track adoption. Data will be sourced, aggregated and visualised to inform key stakeholders, including patients, healthcare professionals, policy-makers and health system managers. The index will be published online and through industry and academic collaborator fora, as well as mainstream and health-specific media, thus raising awareness and adoption of $\mathrm{CH}$.

Patient Pairing: Where relevant and appropriate, students will be paired with a patient who will represent and offer access to a relevant patient organisation. This will inform the $\mathrm{PhD}$ project, encourage patient impact and offer access to patients for dissemination.

Health Hack: A key feature of CHESS is a Health 'Hack' to produce a solution for a particular patient "need" within a short space of time providing an unparalled interdisciplinary, intersectoral and translational training experience for students while encouraging a focus on impact and stakeholder engagement.

Web-based Project Pathway: Mentored by an industry leader, CATCH students will create a project pathway for technology-enabled cancer care spanning need identification through to commercialisation including tools and techniques developed throughout CATCH.

Working with Patient Populations: A hands-on workshop module brings students and patients together to identify the patient need. The active participation of patient representatives is crucial, not as mere "lectures" but as a collaborative process using User Centred Design principles (Shah \& Robinson, 2007).

\section{Discussion}

The benefits of the programmes are twofold. Most obviously, the student creates a new and broader understanding of $\mathrm{CH}$ for themselves. Beyond that, however, is the benefit felt at the sectoral level as the programmes develop a new and highly skilled community of practice in $\mathrm{CH}$. We discuss some of the factors affecting programme design and success.

\subsection{Role of non-academic sector in the training programme}

A key aspect of the programmes, is the intense involvement of the non-academic partners from the outset with the definition of the research objectives. For example, one of the employees in a digital health company created the seed of the description of a $\mathrm{PhD}$ project based on her own chronic health condition. The programmes boast 19 non-academic partners representing private enterprise (SME and MNC) as well as healthcare delivery. Private enterprise partners offer insights into the process of bringing a new product to market, while clinical partners provide a purchaser/end-user view and care pathway/patient experience insights. Patients and policy-makers also contribute to the delivery of such innovative, rounded, and ultimately translatable training programmes. Such collaboration is 
essential to create the climate for interdisciplinary learning. Each of these individuals, however, would have originally been educated in a silo and will have preconceived perceptions of their professional role. It is essential that they learn to trust, and work together with, their patients and stakeholders to develop a new understanding of $\mathrm{CH}$ which will enhance their work going forward. Aacademics and non-academics designed the programme such that skills acquired match the employment needs of both sectors. While it is expected that academic partners take on training delivery, within these innovative programmes, non-academics are also heavily involved. They recruit and train $\mathrm{PhDs}$, host site visits, run transferrable skills modules (e.g. innovating in an emerging market). In fact, one CHESS industry partner, Salumedia, has taken on formal responsibility for training as a whole. While scientific modules and $\mathrm{PhD}$ training are managed by academia, Salumedia ensures that training is truly focused on career opportunities in the non-academic sector, as well as the academic. Secondments are hosted by industry partners who also form part of hosted student's Doctoral Studies Panel (DSP), bringing industry expertise to an academic process. Industry partners provide keynote speakers for training events such as summer schools and lead dissemination efforts to key clinical and industry audiences. Clinical partners source cohorts for studies, while patient leaders contribute to user experience training by setting real-life problems that are addressed by the students in training events. Healthcare policy-maker masterclasses round out student networks and influencing skills.

\subsection{Joint supervision}

A training committee (balanced by sector, discipline, gender and geography) ensures a common supervision structure while accomodating each institution's $\mathrm{PhD}$ structures. The DSP supports and enhances supervisor-student relationships, monitors progress of their doctoral studies, and provides advice and support. Each DSP includes a minimum of 3 members: the main supervisor (host organisation), the second supervisor (secondment host 'in the other sector'), and another academic mentor from host or collaborating institution.

\subsection{Career Development}

Each student works with the DSP to formulate his/her own Personal Career Development Plan. Although each host organisation can propose its own model, a template is provided and compulsory items to be included are: 1) Training Plan including formal education, acquired skills, and developed expertise; 2) Professional and Career Development Plan (PCDP) including research skills and awareness, personal effectiveness and development, team-working and leadership, ethics and social understanding, career management, communication skills, entrepreneurship and innovation; 3) Meeting Record Report. All PCDP and DSP meeting records are formally recorded throughout the programme. 


\subsection{Exposure of recruited researchers to different environments}

Sectoral: CHESS and CATCH respond to industry requirements for researchers who can operate in an inter-disciplinary context across academia, healthcare, and other industries. Intersectoral secondments, site visits, keynote speakers, and DSPs ensure meaningful exposure to the healthcare, academic, and industry sectors. Training modules addressing key transferable skills common to all fields (e.g. inter-sectoral communications, management of IP rights, exploitation of research results, ethics, and outreach) maximise students' ability to exploit these exposures for career, research, and innovation purposes.

Disciplinary: Introductory modules during the orientation conference (disciplinary 101's such as "An introduction to business models" or "An introduction to health science") expose students to a range of disciplinary approaches and recreate the discipline's research environment to ensure understanding and therefore communication across disciplines.

Geographic: With up to 8 countries in each consortium including multi-national partners, students gain exposure to multiple research and commercial approaches that may be shaped by geography. Summer schools held in different countries include local site visits and keynote speakers showcasing different cultures, lifestyles and experiences.

\subsection{Formation of sustainable Training Networks:}

Both programmes create training networks that span geographies, disciplines and sectors with events and networks spilling into other fourth level programmes run by consortia partners. They improve the personal and career development of students beyond graduation, and networks will exist long after programme funding has ceased through future projects, funding applications and other European training programs such as COST, and more.

\subsection{Data Openness:}

Both programmes are part of the European Data Pilot. Students are trainined on new approaches to foster the sharing and openness of research data.

\section{Conclusion}

The complex challenges facing society, including those of sustainable, equitable healthcare, mean that there is a need for a different kind of $\mathrm{PhD}$ graduate. This need is best summarised as a "T-shaped" graduate with deep disciplinary expertise allied to an ability to understand and add value in an interdisciplinary world. New, structured $\mathrm{PhD}$ training programmes are required in order to deliver on this agenda. They must be interdisciplinary, intersectoral and innovative in both their design and delivery. Such programmes must include new kinds of modules that offer hands-on exposure to real world interdisciplinary challenges, encourage intersectoral communication, and offer routes to industry and societal impact. Both training programmes presented here speak to the necessity of integrating the patient into the 
development of health technologies. The emphasis placed on the patient throughout the programmes shows how the patient should be viewed, as core informants and educators.

We have not, as yet, attempted to transfer learnings or structures from these programmes into non-health related areas. It may well be that our success in integrating disciplines and sectors depends on an evident public good goal, such as that of sustainable healthcare. It should noted that the dual requirements of depth and breadth place a greater burden on the student. This is offset by increased training and support structures, but we are nevertheless aware of the need to constantly monitor students for over-load or burnout.

Truly interdisciplinary programmes at fourth level will incorporate six core elements: exposure to different environments, joint supervision, a genuine role for the non-academic sector, career development training and planning, data openness, and the development of a sustainable training network beyond the life of the programme. We expect this type of programme become more ubiquitous across Europe as funders, employers and indeed, students themselves, expect more rounded and practice-focused training experiences.

\section{References}

Accenture (2012) Making the case for $\mathrm{CH}$, Report. https://www.accenture.com/ieen/ /media/Accenture/Conversion-

Assets/DotCom/Documents/Global/PDF/Industries_11/Accenture-Making-Case-

Connected-Health.pdf. 22 April 17

Anderson J. (2007) Social, ethical and legal barriers to e-health. Int J Med Inf; 76: 480-3.

AT\&T (2012). Telehealth: Breaking down barriers for more CH care, Report. 22 April 17 https://www.corp.att.com/healthcare/docs/connected_hc.pdf .

CAIPE- Centre for the Advancement of Interprofessional Education (2016) April 222017.

Caulfield, B.M. \& Donnelly, S. (2013). What is CH and Why Will it Change your practic?. QJM. 106(8):703-7.

CORDIS (2017) http://cordis.europa.eu/home_en.html 22 April 17.

Enject (2016) $\mathrm{CH}$ in Europe, where are we now? http://enject.eu/wpcontent/uploads/2016/12/Report-Final.pdf 22 April 17

Ertmer, P. A., \& Newby, T. J. (1993). Behaviorism, cognitivism, constructivism: Comparing critical features from an instructional design perspective. 21 April 17. http://www.csiss.org/SPACE/workshops/2007/UCSB/docs/ertmer_newby1993.pdf

Kolb, D.A. (1984), Experiential learning: experience as the source of learning and development, Englewood Cliffs, NJ: Prentice Hall.

Newswander K. \& Borrego, M. (2009) Engagement in two interdisciplinary graduate programmes. High Educ 58:551-562.

Shah, S. \& Robinson, I. (2007), Benefits of and barriers to involving users in medical device technology development and evaluation, IJTA Health Care, 23:1, 131-137.

Swan, M. (2009) Emerging Patient-Driven Health Care Models, Int J Environ Res Public Health. 6(2): 492-525. 
UK Department of Health (2011), Whole Systems Demonstrator, Headline Findings, https://www.gov.uk/government/uploads/system/uploads/attachment_data/file/215264/d h_131689.pdf 22 April 17.

United Nations, Department of Economic and Social Affairs, Population Division (2015). World Population Prospects: The 2015 Revision, Key Findings and Advance Tables. https://esa.un.org/unpd/wpp/publications/files/key findings_wpp_2015.pdf 22 April 17. 